\title{
Investigation of inertia-gravity waves in the upper troposphere/ lower stratosphere over Northern Germany observed with collocated VHF/UHF radars
}

\author{
A. Serafimovich ${ }^{1}$, P. Hoffmann ${ }^{1}$, D. Peters ${ }^{1}$, and V. Lehmann ${ }^{2}$ \\ ${ }^{1}$ Institute of Atmospheric Physics, Kühlungsborn, Germany \\ ${ }^{2}$ Meteorological Observatory, Lindenberg, Germany \\ Received: 6 July 2004 - Published in Atmos. Chem. Phys. Discuss.: 5 August 2004 \\ Revised: 18 November 2004 - Accepted: 31 January 2005 - Published: 4 February 2005
}

\begin{abstract}
A case study to investigate the properties of inertia-gravity waves in the upper troposphere/lower stratosphere has been carried out over Northern Germany during the occurrence of an upper tropospheric jet in connection with a poleward Rossby wave breaking event from 17 19 December 1999. The investigations are based on the evaluation of continuous radar measurements with the OSWIN VHF radar at Kühlungsborn $\left(54.1^{\circ} \mathrm{N}, 11.8^{\circ} \mathrm{E}\right)$ and the $482 \mathrm{MHz}$ UHF wind profiler at Lindenberg $\left(52.2^{\circ} \mathrm{N}\right.$, $14.1^{\circ} \mathrm{E}$ ). Both radars are separated by about $265 \mathrm{~km}$. Based on wavelet transformations of both data sets, the dominant vertical wavelengths of about $2-4 \mathrm{~km}$ for fixed times as well as the dominant observed periods of about $11 \mathrm{~h}$ and weaker oscillations with periods of $6 \mathrm{~h}$ for the altitude range between 5 and $8 \mathrm{~km}$ are comparable. Gravity wave parameters have been estimated at both locations separately and by a complex cross-spectral analysis of the data of both radars. The results show the appearance of dominating inertia-gravity waves with characteristic horizontal wavelengths of $300 \mathrm{~km}$ moving in the opposite direction than the mean background wind and a secondary less pronounced wave with a horizontal wavelength in the order of about $200 \mathrm{~km}$ moving with the wind. Temporal and spatial differences of the observed waves are discussed.
\end{abstract}

\section{Introduction}

The upper troposphere and lower stratosphere are characterized by the appearance of gravity waves with different scales. It is widely accepted that jet streams in the tropopause region itself are one of the main sources for these waves. Due to the exponential decrease of the density with the altitude, the upward propagation of the gravity waves is associated with

Correspondence to: A. Serafimovich

(serafimovich@iap-kborn.de) an increase of their amplitudes till they are breaking. Associated with the wave breaking and the accompanying deposition of momentum and energy in the background flow, the dynamical and thermal structures above the source region up to mesospheric heights as well as downward at tropospheric heights are essentially influenced. However, the quantitative aspects of the propagation of the waves, their interactions with the mean winds and other waves as well as their generation are poorly understood at present. For a review on the current knowledge on gravity waves we refer to Fritts and Alexander (2003).

Particularly in the lower stratosphere, transport and mixing processes due to inertia-gravity waves (IGW) with frequencies close to the Coriolis frequency are expected to be important, as shown by Plougonven et al. (2003). Here we are focusing on the investigation of these waves which can be characterized by periods of several hours and horizontal wavelengths of more than hundred kilometers. As reported by Sato et al. (1997), Thomas et al. (1999), Röttger (2000), inertia-gravity waves are observed in various regions of the Earth. The gravity waves are connected with a number of different forcing mechanisms, such as ageostrophic adjustment, orographic forcing, frontal activity, deep convection or jet instability (Pavelin and Whiteway, 2002). These waves can alter the mean stratospheric temperature locally with amplitudes up to $10 \mathrm{~K}$, which supports for instance at polar latitudes the generation of Polar Stratospheric Clouds during the winter months as investigated by Dörnbrack et al. (2002) and Buss et al. (2004).

A first case study to investigate the appearance of long period inertia-gravity waves in connection with a jet stream in the upper troposphere during a Rossby wave breaking event has been carried out at Kühlungsborn from 17-19 December 1999 in the frame of the LEWIZ campaign (Peters et al. (2003), hereafter P2003). The results were based on a series of 17 radiosondes released every $3 \mathrm{~h}$ supported by VHF radar observations at the same location. It has been found that the

(C) 2005 Author(s). This work is licensed under a Creative Commons License. 


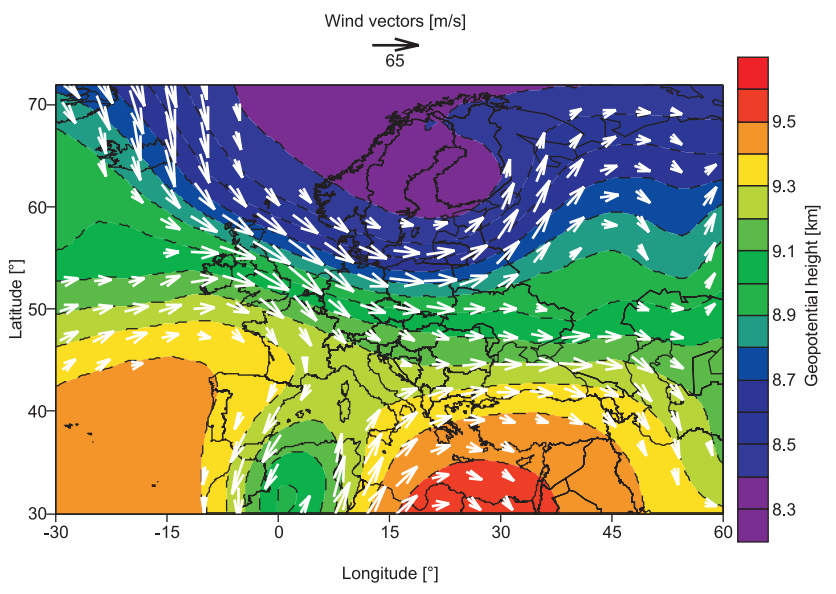

Fig. 1. Wind vectors and geopotential height derived from ECMWF analyses for the $300 \mathrm{hPa}$ level at 18 December 1999, 12:00 UT. Vectors are plotted only for wind speeds larger than $20 \mathrm{~ms}^{-1}$.

source of the dominating inertia-gravity wave with a period of about $12 \mathrm{~h}$ is placed in the region of the zonal wind jet just below the tropopause.

In extension of P2003, the main objectives of this study are to get more insight into the structure of gravity waves with shorter periods in the upper troposphere which cannot be resolved by 3 -hourly radiosondes. These investigations are done with detailed analyses of the data of two VHF/UHF radars over Northern Germany at Kühlungsborn and Lindenberg, separated by about $265 \mathrm{~km}$, to examine the main characteristics of inertia-gravity waves. Here we will consider both radars as "collocated" due to the long horizontal wavelengths of the inertia-gravity waves investigated. Furthermore, for the estimation of gravity wave parameters different methods such as wavelet transforms, hodograph analyses, rotary spectra and the Stokes-parameter technique have been tested and applied on the wind data at each radar location, available with a resolution of $30 \mathrm{~min}$. In this way the influence of possible vertical shear in the background wind, introduced by Hines (1989), will be take into account. These results are then compared with cross-spectral analyses of the data from both radars to identify common wave events and to discuss temporal and spatial differences of the observed waves in connection with the findings of P2003.

The paper is organized as follows. In Sect. 2 the meteorological background for inertia-gravity waves events is discussed and the parameters of the radars are briefly described. Then we summarise in Sect. 3 the techniques used for data processing and the methods to estimate gravity wave parameters applied to the radar measurements at each location supplemented by the cross-spectral analyses of collocated radar measurements. Section 4 is devoted to the final estimation of inertia-gravity wave characteristics and the discussion of the results. In Sect. 5, we summarize our main results and give some concluding remarks.

\section{Observations during a case study over Northern Ger- many from 17-19 December 1999}

The investigations are based on observations made with two collocated radars, the OSWIN-53.5 MHz-VHF radar located at Kühlungsborn, and the $482 \mathrm{MHz}$-wind profiler at Lindenberg. Details of the radar parameters used are summarized in Table 1.

The OSWIN VHF radar has been operating at Kühlungsborn since autumn 1999. The radar system was designed for continuous measurements and is running either in the spaced antenna (SA) or in the Doppler Beam Swinging mode (DBS). The antenna array consists of 144 four-element Yagis resulting in a transmitting halfpower beam width of $6^{\circ}$. The beam is steerable in the vertical direction and towards the North, East, South, and West with an off-zenith angle of $7^{\circ}$. For the investigations presented here, we used 1024 point complex time series sampled with $0.05 \mathrm{~s}$. The radar resolves a height region from 1 to $18 \mathrm{~km}$. Data are averaged over $30 \mathrm{~min}$ for further investigations.

The $482 \mathrm{MHz}$ wind profiler belongs to the Meteorological Observatory Lindenberg of the German Weather Service (DWD). The wind profiler is a fully coherent Doppler radar system with an additional RASS component to estimate sound virtual temperatures (Gurvich et al., 1987). It has been in operation since August 1996 as a prototype system for an operational DWD profiler network (Lehmann et al., 2003). Wind measurements are carried out in the DBS mode using the vertical and four oblique beam directions with an off-zenith angle of $15^{\circ}(\mathrm{Hogg}$ et al., 1983). In contrast to the data processing technique used with the OSWIN VHF radar a statistical method for the incoherent integration of 17 individual spectra has been applied to reduce the noise variance and to suppress intermittent clutter contamination (Merritt, 1995).

The results have been obtained during a field campaign carried out from 17 to 19 December 1999. The planning of the measuring campaign was based on forecasts from the German Weather Service.

Fig. 1 shows wind vectors larger than $20 \mathrm{~ms}^{-1}$ and geopotential heights derived from the ECMWF data at 12:00 UT on 18 December 1999 for the $300 \mathrm{hPa}$ level corresponding to a height of approx. $9 \mathrm{~km}$. The meteorological situation was connected with a poleward breaking Rossby wave, classified as a P2 event (Peters and Waugh, 1996), and leading to a strong eastward directed jet near the tropopause over Northern Germany. For a more detailed description of this event we refer the reader to P2003 and Zülicke and Peters $\left(2004^{1}\right)$.

In Fig. 2 height-time cross-sections of the smoothed zonal and meridional wind are presented for both locations. The eastward directed zonal wind over Kühlungsborn (Fig. 2a)

\footnotetext{
${ }^{1}$ Zülicke, Ch. and Peters, D.: Inertia-gravity waves driven by a poleward breaking Rossby wave, J. Atmos. Sci., submitted, 2004.
} 
Table 1. Parameters of the VHF radar OSWIN at Kühlungsborn and the UHF wind profiler at Lindenberg.

\begin{tabular}{lll}
\hline & OSWIN VHF radar & UHF wind profiler \\
\hline Geographical location & $54.1^{\circ} \mathrm{N}, 11.8^{\circ} \mathrm{E}$ & $52.2^{\circ} \mathrm{N}, 14.1^{\circ} \mathrm{E}$ \\
Operating frequency & $53.5 \mathrm{MHz}$ & $482 \mathrm{MHz}$ \\
Peak power/duty cycle & $\sim 90 \mathrm{~kW} / 5 \%$ & $16 \mathrm{~kW} / 10 \%$ \\
Transmitting antenna & $144 \mathrm{Yagi}$ array & Phased array $(\mathrm{CoCo})$ \\
Antenna aperture (area) & $1900 \mathrm{~m}^{2}$ & $140 \mathrm{~m}^{2}$ \\
Half-power beam width & $6^{\circ}$ & $3^{\circ}$ \\
Pulse length & $4 \mu \mathrm{s}$ & $3.3 \mu \mathrm{s}$ \\
Nof transmitter/receiver & 6 & 1 \\
Code & Single pulse & 8 -bit-Complementary code \\
Coherent integration & 128 & 30 \\
Vertical resolution & $300 \mathrm{~m}$ & $250 \mathrm{~m}$ \\
Altitude range & $1-18 \mathrm{~km}$ & $2.7-16.0 \mathrm{~km}$ \\
Time resolution & $\sim 1 \mathrm{~min}$ & $\sim 33 \mathrm{sec}$ \\
Methods & DBS, (SA) & $\mathrm{DBS}$ \\
\hline
\end{tabular}
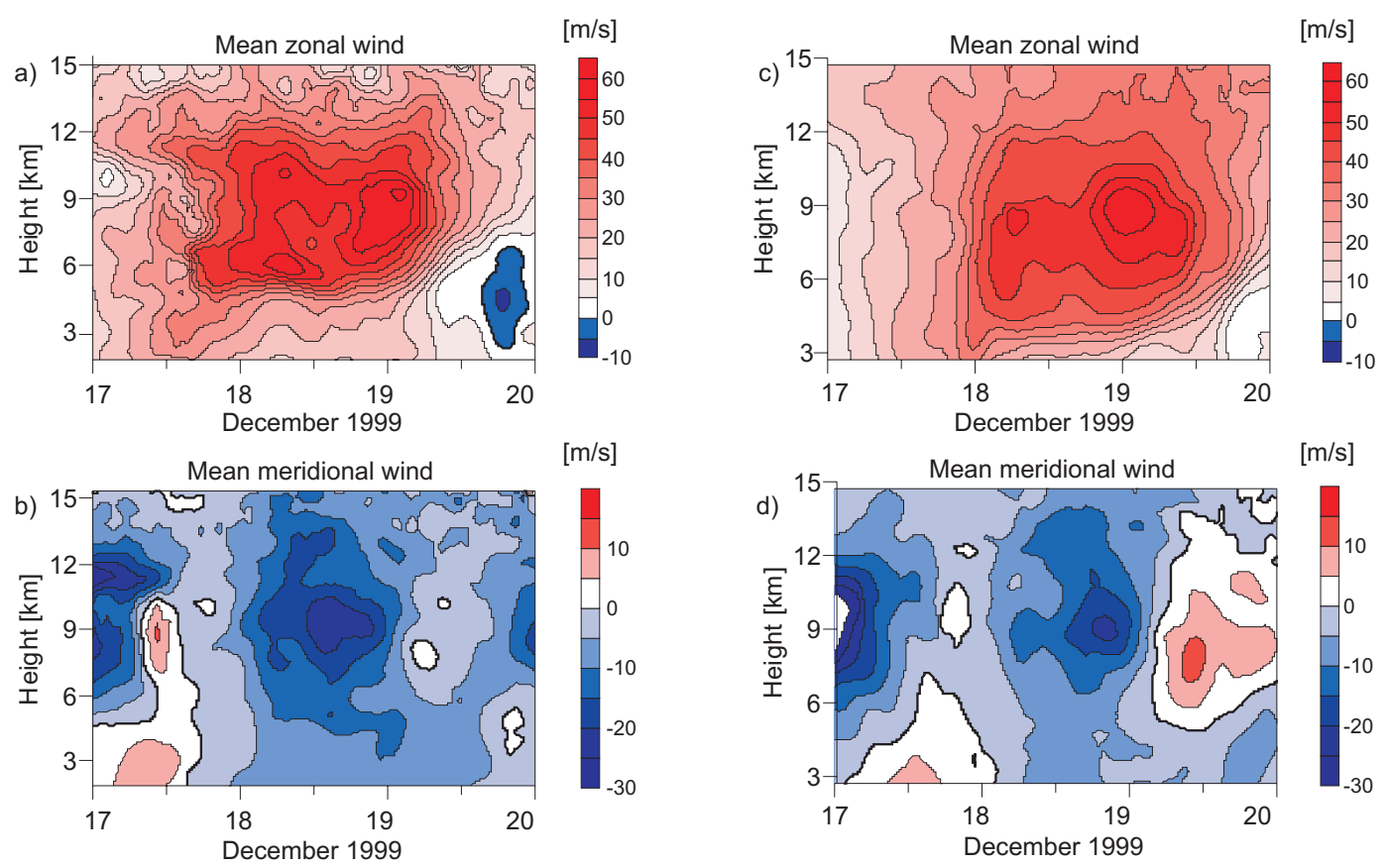

Fig. 2. Mean zonal and meridional winds measured at Kühlungsborn (a, b) [after Peters et al. (2003)] and Lindenberg (c, d) from 17-19 December 1999. The data are smoothed using a low-pass filter with cut off frequencies corresponding to $4 \mathrm{~h}$ in time and $600 \mathrm{~m}$ in altitude.

increases until 19 December, 00:00 UT and then decreases. The maximum jet stream reaches values of more than $50 \mathrm{~ms}^{-1}$ at heights between 6 and $10 \mathrm{~km}$. The meridional component (Fig. 2b) shows southward directed winds with maxima of more than $20 \mathrm{~ms}^{-1}$ at 18 December (12:0018:00 UT). With the onset of the jet, the winds rotate to eastward directed during the jet maximum and turn back with the decreasing jet.

The observations with the wind profiler at Lindenberg (Fig. 2c, d) separated by about $265 \mathrm{~km}$ from the
Kühlungsborn VHF radar, show the occurrence of the eastward and southward directed jets at nearly the same times and altitudes, whereas e.g. the reversal of the meridional winds to northward directed winds on 19 December seems to be slightly stronger at Lindenberg. Detailed comparisons with the radiosondes (see P2003) and the 6 hourly - ECMWF analyses winds (not shown here) result in good qualitative agreement but the radar measurements resolve a higher variability due to the better time resolution. In the next section we will describe the data analysis techniques to derive wind 
perturbations necessary for the estimation of the gravity wave parameters.

\section{Inertia gravity wave parameters estimation}

\subsection{Data processing to separate wind perturbations}

The calculation of gravity wave parameters is based on wind perturbations, which have been estimated from the wind measurements after linear interpolations to substitute missing values. In general the perturbations can be described by variations of amplitudes $a(x, y, z, t)$ of the wind components

$a(x, y, z, t)=a_{0} \cdot \exp \left(i\left(k x+l y+m z-\omega_{o b} t\right)\right)$,

where $a$ can be perturbations of zonal $u^{\prime}$ or meridional $v^{\prime}$ winds, temperature $T^{\prime}$ or pressure $p^{\prime}$ with a time $t$. The zonal, meridional and vertical wave numbers are denoted by $k, l$ and $m$ in $x$-, $y$-, $z$-directions, respectively, $i=\sqrt{-1}$, and $\omega_{o b}$ is the wave frequency, observed at a fixed location. With the Doppler relation

$\omega_{o b}=\omega_{i n}+\bar{U} k_{h}$,

$\omega_{o b}$ depends on the intrinsic frequency $\omega_{i n}$, the horizontal wave number $k_{h}=\sqrt{k^{2}+l^{2}}$ and the mean background horizontal wind component $\bar{U}$ given in the same direction as the horizontal wave number $k_{h}$. Corresponding to Zink and Vincent (2001), we adopt here the convention of a positive intrinsic frequency $\omega_{i n}$ and define a negative vertical wave number $m$ for waves propagating energy upwards.

Normally, the perturbations are characterized by a superposition of atmospheric waves with different frequencies. In order to estimate inertia-gravity wave parameters individual waves have to be separated or isolated by the application of reasonable band-pass filtering methods. To detect the presence of a wave in the data and to avoid arbitrary choices of inappropriate filter parameters a wavelet transform has been applied (Torrence and Compo, 1998; Zink and Vincent, 2001). This technique is becoming a common tool for analyzing localized variations due to their possibilities to resolve the waves in frequency domain as well as in the time or height.

The term wavelets refers to a family of small waves generated from a single function, the so-called mother wavelet, by a series of dilations and translations. To be called a "wavelet" a function should be admissible. This means for an integrable function that its average should be zero (Farge, 1992). Wavelets are well localized in time and frequency spaces.

The wavelet transform itself denotes the correlation between the original function $a(z, t)$, where $a(z, t)$ represents the perturbations (Eq. 1) observed at a fixed location, either for a constant height or time, and the version of the mother wavelet $g\left(\frac{t-b}{s}\right)$, which is scaled with a factor $s$ and translated by a dilation $b$. The choice of the mother wavelet is an important point in the wavelet transform. Since the horizontal wind perturbations of the gravity waves can be considered as amplitude-modulated sine waves, the selection of the Morlet wavelet seems to be reasonable, because the Morlet wavelet is nothing else than the plane wave modulated by a Gaussian. Its representations in time, $g(t)$, and Fourier space, $G(\omega)$, are given by

$$
\begin{aligned}
& g_{\text {morlet }}(t)=\pi^{-1 / 4} e^{i \omega_{0} t} e^{-t^{2} / 2} \\
& G_{\text {morlet }}(s \omega)=\pi^{-1 / 4} H(\omega) e^{-\left(s \omega-\omega_{0}\right)^{2} / 2},
\end{aligned}
$$

where $\omega_{0}$ is the nondimensional frequency, later also called and used as the order of the wavelet, $H(\omega)$ is Heaviside step function, which is equal to 1 if $\omega>0$ and $H(\omega)=0$ otherwise, and $s$ is wavelet scale.

By the convolution theorem, the wavelet transform $W(t, s)$ was carried out in the Fourier domain and has been calculated by the inverse Fourier transform $F^{-1}$ of the product:

$W(t, s)=F^{-1}\left(G^{*}(s \omega) F(\omega)\right)$,

where $F(\omega)$ is the Fourier transform of the signal, and $G^{*}(s \omega)$ is the conjugated Fourier transform of the scaled wavelet.

Wavelet transforms have been applied on time series of the zonal and meridional winds for constant height ranges as well as on wind profiles versus height for fixed time intervals. The significance of the results depends on the mother wavelet and the sample length, which is reduced at the boundaries of the time and height intervals, respectively. To minimize such border effects, we decided to apply the Paul wavelet on the wind profiles due to their short record lengths:

$g_{\text {paul }}(t)=\frac{2^{n} i^{n} n !}{\sqrt{\pi(2 n) !}}(1-i t)^{-(n+1)}$
$G_{\text {paul }}(s \omega)=\frac{2^{n}}{\sqrt{n(2 n-1) !}} H(\omega)(s \omega)^{n} e^{-s \omega}$,

where $n$ is the order taken to be 4 to make the wavelet "admissible". This wavelet leads to a better height localization of the dominant vertical wavelengths and smaller influences of the border effects, as shown by Torrence and Compo (1998). For the wavelet transforms of time series for constant heights the Morlet wavelet (with the order of $\omega_{0}=6$ due to the admissibility condition) has been applied resulting in a better frequency localization of the dominant observed periods. With the Morlet wavelet the influence of limited data on the borders are larger in comparison with the Paul wavelet, but there are no problems to extend the time series. Details of the choice of the wavelet function can be found in Torrence and Compo (1998).

Because the wavelet functions are mostly complex, the wavelet transform $W(t, s)$ is also complex, therefore one can define the wavelet power spectrum as $|W(t, s)|^{2}$. It should 

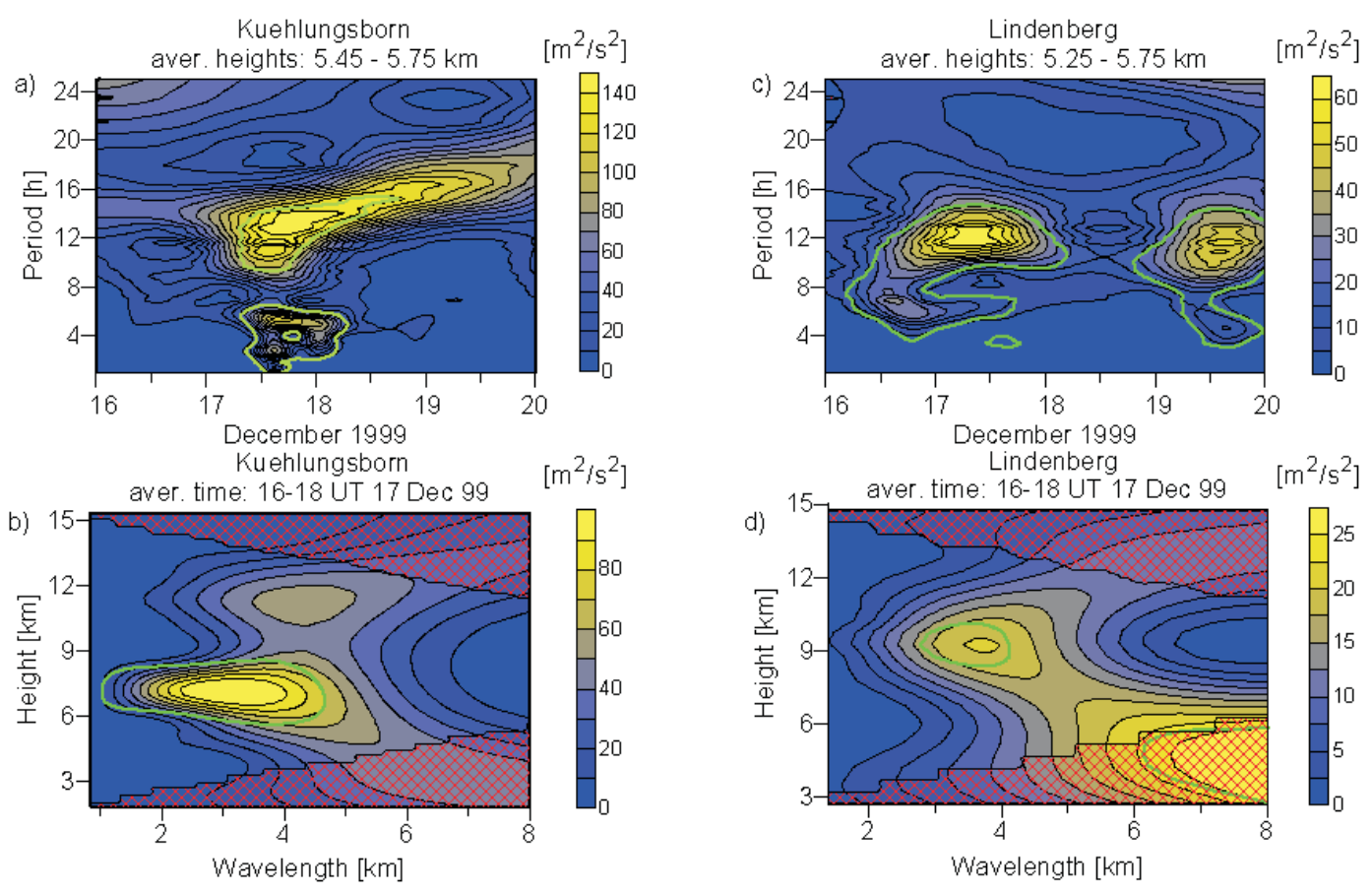

$-95 \%$ significance level
- boundary effects region

Fig. 3. Averaged sum of wavelet power spectra of the zonal and meridional winds measured at Kühlungsborn (a, b) and Lindenberg (c, d), in the upper panel (a, c) as Morlet wavelet transforms of the time series averaged over the altitude ranges (a) $5.45-5.75 \mathrm{~km}$ or (c) $5.25-5.75$ $\mathrm{km}$; in the lower panel $(\mathrm{b}, \mathrm{d})$ as Paul wavelet transforms of the vertical wind profiles averaged with a time, respectively.

be remarked that the wavelet scale $s$ does not directly correspond to a Fourier period $\lambda$. The relationship between the Fourier period and the equivalent wavelet scale can analytically be derived by substituting a cosine wave of a known frequency into Eq. (5) and calculating at which scale $s$ the wavelet power spectrum has a maximum. For the Morlet wavelet with $\omega_{0}=6$, this leads to a value of $\lambda=1.03 \mathrm{~s}$ and for the Paul wavelet of the order 4 this leads to a value of $\lambda=1.39 s$ (Torrence and Compo, 1998). Using Eq. (5) one can calculate the continuous wavelet transform for different scales $s$ at all time points simultaneously to estimate efficiently the dependence of dominant periods on the time.

The results of the wavelet analysis are presented by the sum of wavelet power spectra of the zonal and meridional wind components in Fig. 3 measured at Kühlungsborn (a, b) and Lindenberg (c, d). The bold green line outlines the region with 95\% significance level. The red net covers the area where boundary effects appear. From the wavelet transform of the wind time series averaged in height from $5.45 \mathrm{~km}$ to $5.75 \mathrm{~km}$ at Kühlungsborn and from $5.25 \mathrm{~km}$ to $5.75 \mathrm{~km}$ at Lindenberg, shown in the upper panel (a and c) of Fig. 3, we detect suitable similarities at both locations with significant periods between $4-7 \mathrm{~h}$ and 9-14 $\mathrm{h}$ including a dominant observed period of about $12 \mathrm{~h}$ and a less pronounced period of about $6 \mathrm{~h}$ on 17 December. We note, that in con- trast to the observed dominant wave with a period of 9-14 h, the shorter waves didn't show up in the two stations at the same time. Here we can only speculate that the sources of these $6 \mathrm{~h}$-waves could be connected with frontal activities or deep convection in the boundary layer, as also discussed at the end of Sect. 4. Furthermore, we find significant vertical wavelengths in the order of 2-4 km near the tropopause region from the wavelet transforms of vertical wind profiles (b and d) averaged in time from 16:00 UT to 18:00 UT on 17 December, for Kühlungsborn as well as for Lindenberg.

Evaluating this information from the wavelet transforms, suitable filter parameters can be defined for different time and height ranges to identify the waves with distinct periods. Band-pass filtering has been carried out using the Fast Fourier transform to extract the signals with dominant frequencies. We divided our analysis in two parts in order to investigate both frequency bands with periods of about $12 \mathrm{~h}$ and about $6 \mathrm{~h}$, respectively. For the study of the waves with dominant observed periods of about $12 \mathrm{~h}$ the filter was constructed (case a) with a bandwidth of 8-18 $\mathrm{h}$ in the time and $2-4.5 \mathrm{~km}$ in the height, whereas in case (b) a filter with a bandwidth of $2-8 \mathrm{~h}$ in the time and $2-4.5 \mathrm{~km}$ in the height has been applied to study waves with periods of about $6 \mathrm{~h}$.

In the first case (a), the resulting perturbations of the zonal and meridional winds at Kühlungsborn and at Lindenberg are 

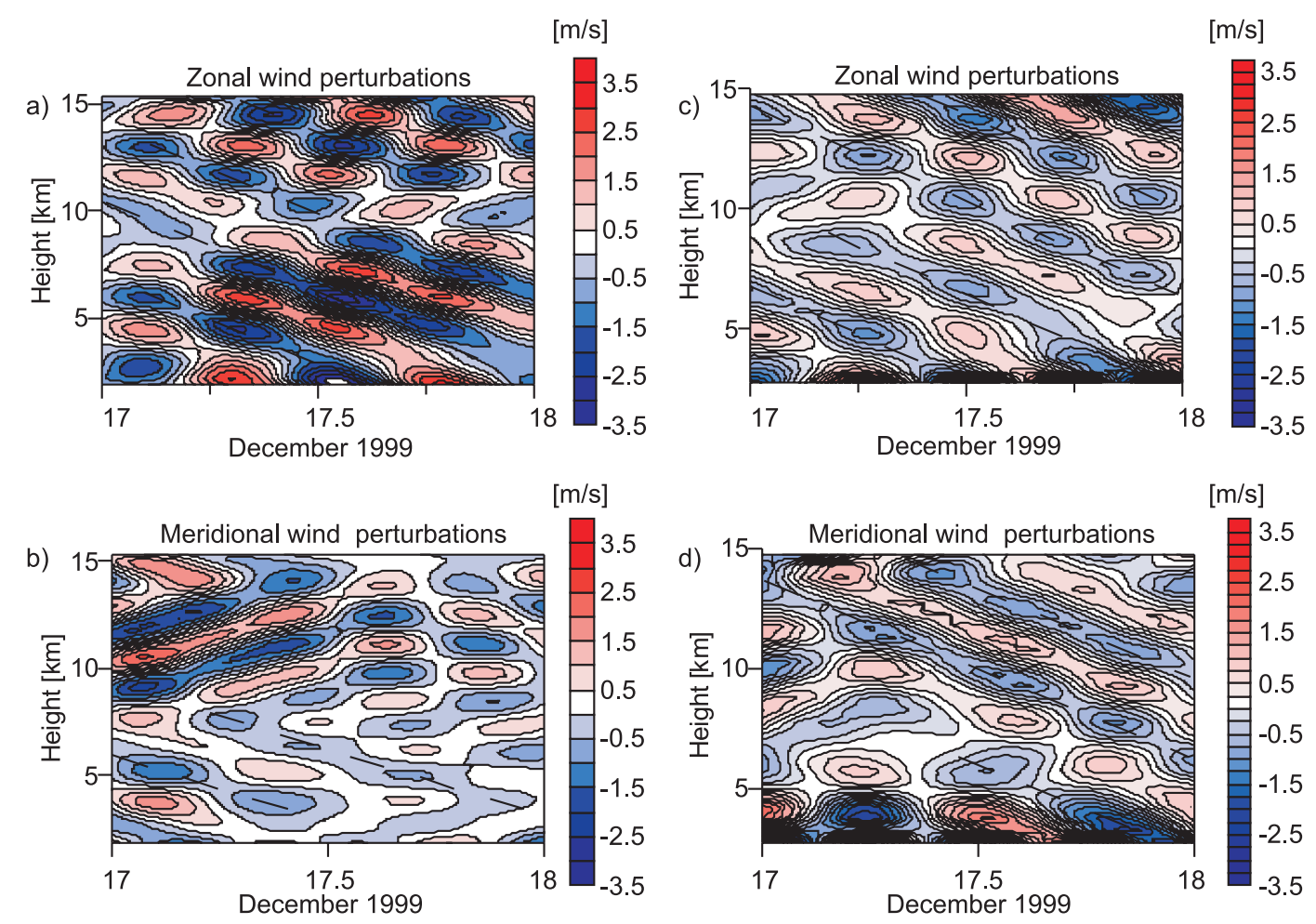

Fig. 4. Zonal (a,c) and meridional (b,d) wind perturbations at Kühlungsborn (a,b) and Lindenberg (c,d) for 17 December 1999 after band pass filtering with bandwidths of $8-18 \mathrm{~h}$ in time and $2-4.5 \mathrm{~km}$ in height.

shown in Fig. 4. From Eq. (1) for a fixed location $x, y$, the dashed lines indicate possible lines of constant phases of the dominant wind perturbations

$m z-\omega_{\mathrm{ob}} t=$ const.

indicating preferred downward phase propagations with the clearest signatures in the perturbations of the zonal winds. The vertical and temporal distances between the phase lines correspond to vertical wavelengths of $\sim 3.3 \mathrm{~km}$ and observed main periods of $\sim 12 \mathrm{~h}$, respectively.

In the secondary case (b) to investigate those waves with periods of about $6 \mathrm{~h}$, the results after the filter application on the zonal and meridional winds measured at Kühlungsborn and Lindenberg are shown in Fig. 5 leading to downward phase propagating perturbations with observed periods of about $6 \mathrm{~h}$ and vertical wavelengths of about $3 \mathrm{~km}$.

The results confirm over an extended height-time-range the main findings from wavelet analyses applied to both wind components for selected time/height ranges at both locations, shown in Fig. 3. This is not obvious in every case, since the wind perturbations shown in Figs. 4 and 5 are characterized by superpositions of atmospheric waves with different frequencies in the selected frequency band and their height/time dependence. The presented wave signatures in Fig. 4 are much more clear than in Fig. 5 as expected after the wavelet analysis with the stronger amplitudes at periods of about $12 \mathrm{~h}$.
The observed downward phase propagations for both waves indicate upward energy propagations, if both frequencies $\omega_{o b}$ and $\omega_{i n}$, connected by the Doppler relation (Eq. 2), have the same signs. However, as shown later in Sect. 3.2.1 and 3.2.2, in agreement with previous investigations in P2003, the hodograph and rotary spectra analyses for the waves with observed periods of $\sim 12 \mathrm{~h}$ lead to downward energy propagation, which is possible if the Doppler-shift is strong enough to turn the phase lines.

The evaluation of the phase propagation derived for each wind component to estimate gravity wave characteristics is only possible if there exist only one dominant wave in a constant mean background wind. The analyses of all gravity wave parameters as shown in the next section are based on the use of zonal as well as meridional winds derived from both filtered data sets.

\subsection{Rotary spectra, hodograph- and Stokes analyses}

For extracting IGW parameters three methods have commonly been used. Each method has its own advantages and disadvantages. The first one is the rotary spectrum, which was first applied to atmospheric IGWs by Thompson (1978). The calculation of the rotary spectrum allows directly to estimate the vertical direction of energy propagation. The second method, the hodograph analysis, is a standard tool in meteorology, described by (Gill, 1982) in connection with 

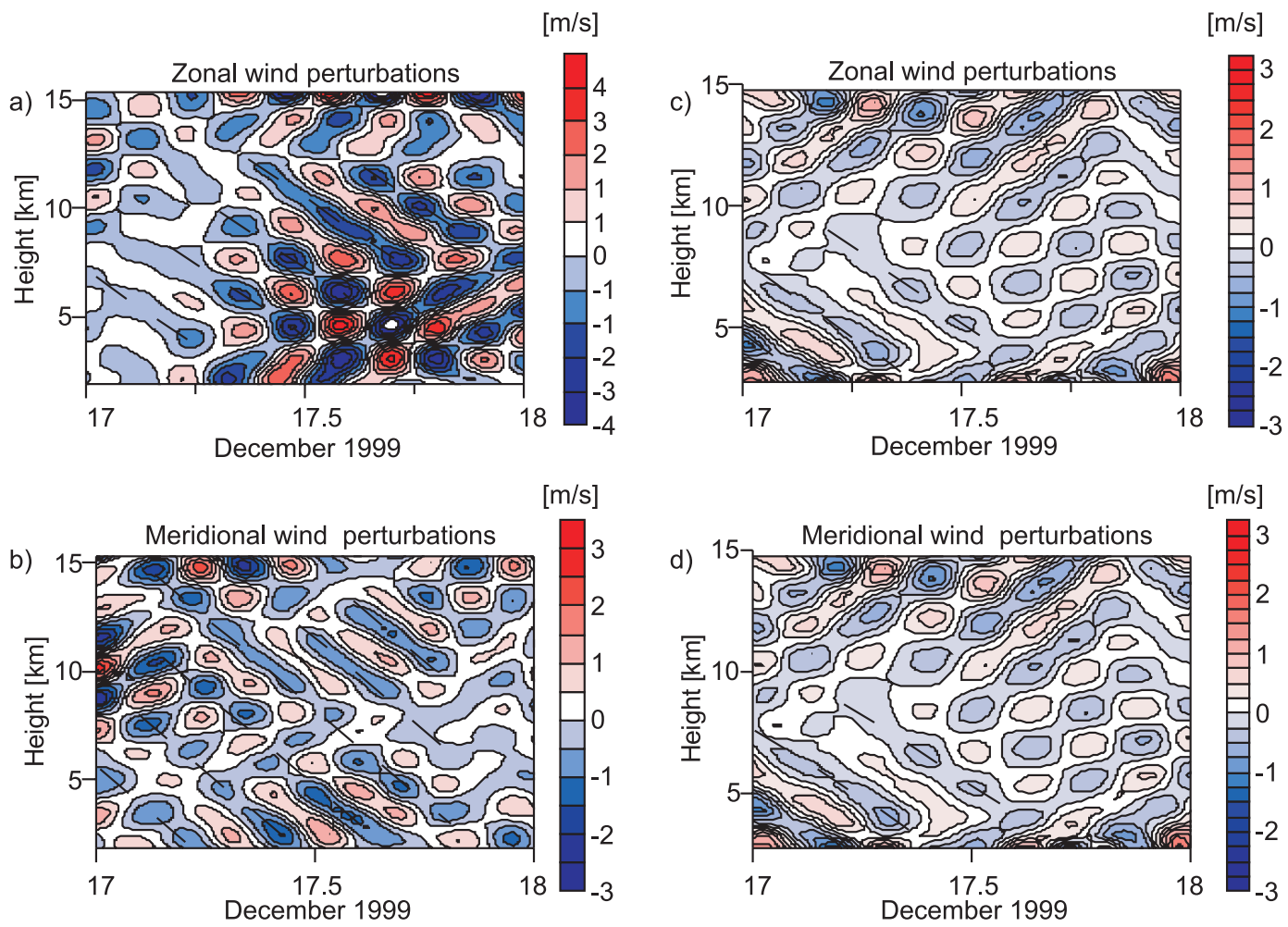

Fig. 5. Zonal (a,c) and meridional (b,d) wind perturbations at Kühlungsborn (a,b) and Lindenberg (c,d) for 17 December 1999 after band pass filtering with bandwidths of $2-8 \mathrm{~h}$ in time and $2-4.5 \mathrm{~km}$ in height.

a rotating fluid and applied first to IGWs by Cot and Barat (1986). The hodograph technique gives wave description in more detail. But this method is only a snapshot and applicable for monochromatic waves. In addition, Vincent and Fritts (1987) presented a Stokes-parameter method which results in a set of gravity wave parameters comparable to the hodograph analysis, but with the possibility to average over time and desired wavenumbers bands, partially polarized waves can be described.

All methods listed above were applied to estimate IGW parameters for both radar measurements carried out at Kühlungsborn and Lindenberg during this case study and are discussed in the next subsections.

\subsubsection{Rotary spectra}

The rotary spectrum technique quantifies how energy is partitioned between upward- and downward-propagating inertia-gravity waves. The rotary spectrum is calculated by the Fourier transform of the complex velocity vector $u^{\prime}(z)+i v^{\prime}(z)$ and leads to an asymmetrical function. Following Guest et al. (2000), this method allows to detect the rotation direction of the horizontal wind perturbations with height using the difference of the negative and positive parts of the spectrum which indicates the presence of an inertiagravity wave in the measurements. The clockwise (counter- clockwise) rotating waves are associated with negative (positive) frequencies in the rotary power spectrum.

The spectra $F(U V(z))$ of the wind perturbations filtered with a bandwidth of $8-18 \mathrm{~h}$ in time and $2-4.5 \mathrm{~km}$ in height are presented in Fig. 6. They show in their negative parts the weaker clockwise rotational power corresponding in the northern hemisphere to an upward energy propagation and in their positive parts the larger counterclockwise rotational power corresponding to a dominating downward directed energy propagation, respectively. These results at both locations are in agreement with the findings in P2003 and Figs. 6 and 10 therein, where they have shown, that the main source of these waves is the placed in the region of the zonal wind jet just below the tropopause. The spectra maximum occur at vertical wavelengths of about $3.3 \mathrm{~km}$. Unfortunately the restricted stratospheric altitude range from the UHF wind profiler data does not permit a significant estimation of rotary spectra above the tropopause.

In contrast to these results, the rotary spectra of the wind variations filtered with a bandwidth of $2-8 \mathrm{~h}$ in the time and $2-4.5 \mathrm{~km}$ in the heights (Fig. 7) show a dominating upward energy propagation. We will discuss these results in context with the estimated wave numbers at the end of Sect. 4. 

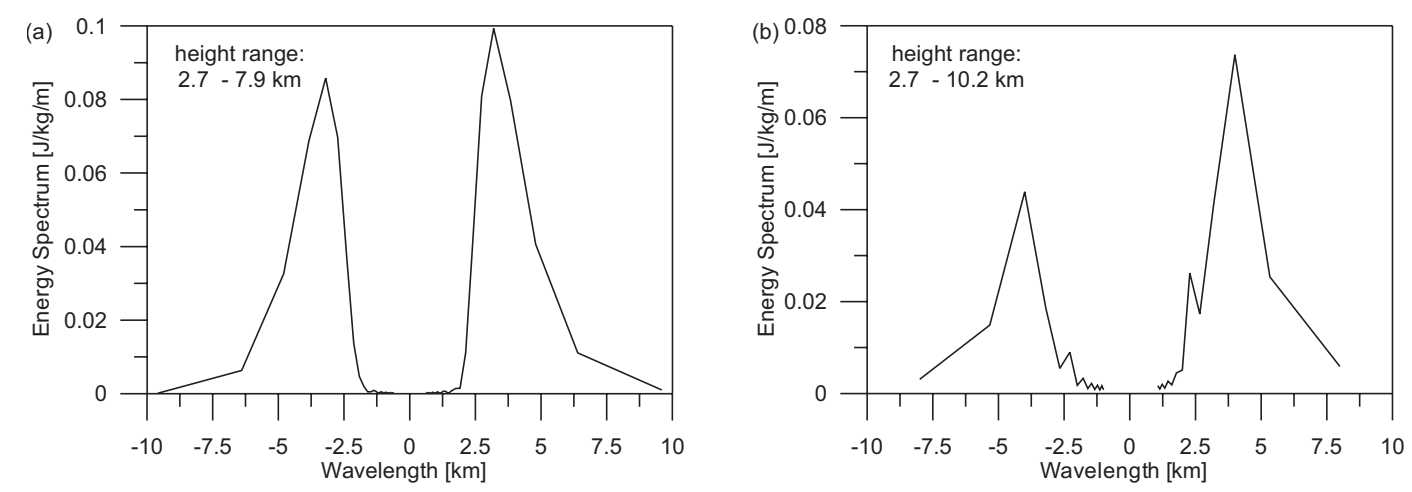

Fig. 6. Results of the rotary spectra averaged for $5 \mathrm{~h}$ at 17 December 1999 starting from 10:00 UT for Kühlungsborn (a) and 19:00 UT for Lindenberg (b) after band pass filtering with bandwidths of $8-18 \mathrm{~h}$ in time and $2-4.5 \mathrm{~km}$ in height.
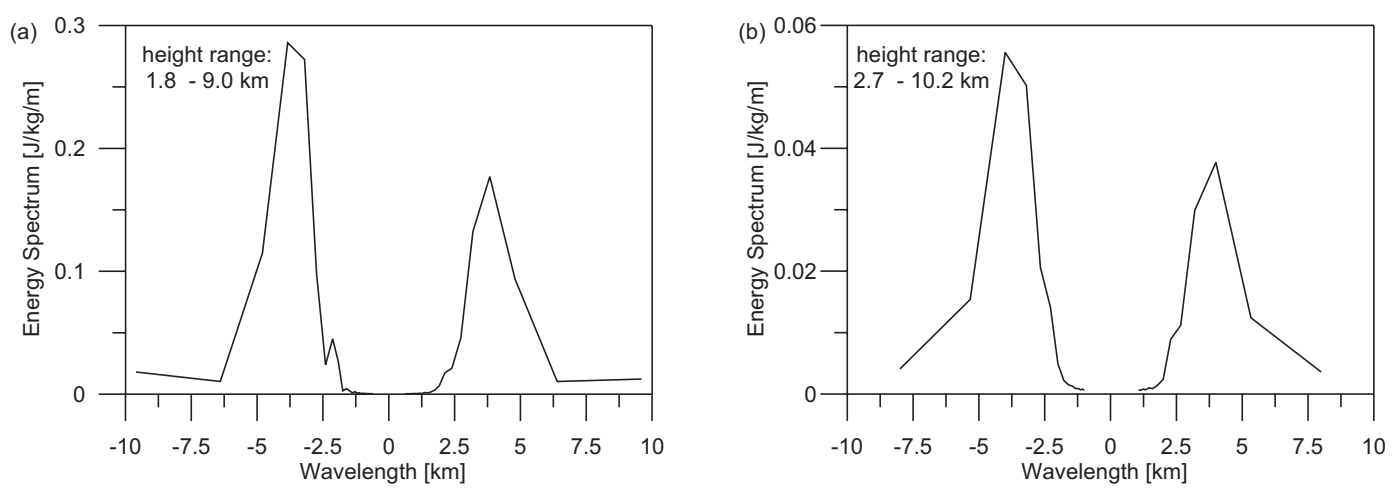

Fig. 7. Results of the rotary spectra averaged for $5 \mathrm{~h}$ at 17 December 1999 starting from 07:00 UT for Kühlungsborn (a) and 09:30 UT for Lindenberg (b) after band pass filtering with bandwidths of $2-8 \mathrm{~h}$ in time and $2-4.5 \mathrm{~km}$ in height.

\subsubsection{Hodograph analysis}

The idea of hodograph analysis is to trace the course of the deviation of the horizontal wind vector with respect to height. If enough points are taken to span one wavelength of an inertia-gravity wave, then an ellipse can be fitted. For inertia-gravity waves, linear theory without any wind shear effects (Gill, 1982) predicts

$v^{\prime}(z)=-i \cdot u^{\prime}(z) \cdot \frac{f}{\omega_{\text {in }}}$,

where $u^{\prime}$ and $v^{\prime}$ are the zonal and meridional components of the horizontal perturbation wind profiles, $f$ is the Coriolis frequency and $\omega_{\text {in }}$ is the intrinsic frequency of the wave.

By the application of the hodograph one can extract the following parameters: the vertical sense of inertia-gravity wave propagation from the rotational sense; the direction of the horizontal wave propagation that is parallel to the major axis of the ellipse and, following Eq. (9), the intrinsic frequency, $\omega_{\text {in }}$, from the ratio of the major to the minor axis of the ellipse. We have to note, that the horizontal wave propagation is uncertain by $180^{\circ}$ without additional temperature information or vertical wind from radars.
The hodograph analysis applied to the wind perturbations of 17 December 1999 to investigate the gravity waves with the observed periods of about $12 \mathrm{~h}$ and therefore filtered with a bandwidth of $8-18 \mathrm{~h}$ in time and $2-4.5 \mathrm{~km}$ in height (Fig. 8), shows a downward energy propagation in the troposphere from the anticlockwise rotational sense at Kühlungsborn and Lindenberg. We derived vertical wavelengths of about $3 \mathrm{~km}$ and intrinsic periods in the order of $\sim 7$ and $\sim 12 \mathrm{~h}$ from the ratios of the major to the minor axis of the fitted ellipses at both locations, respectively. The differences between the hodographs for Kühlungsborn and Lindenberg can be caused by the spatial dependence of the wave characteristics. The variability of the background winds, orographical influences or possible interactions with other waves can lead to the wave changes with propagation from station to station.

Using the wind perturbations filtered with a bandwidth of $2-8 \mathrm{~h}$ in the time and $2-4.5 \mathrm{~km}$ in the heights to investigate the waves with observed periods of about $6 \mathrm{~h}$, the hodographs presented in Fig. 9 show intrinsic frequencies with corresponding periods between 6 and $8 \mathrm{~h}$ and upward energy propagations at both locations in agreement with the rotary spectra in Fig. 7. To demonstrate the stability of the 

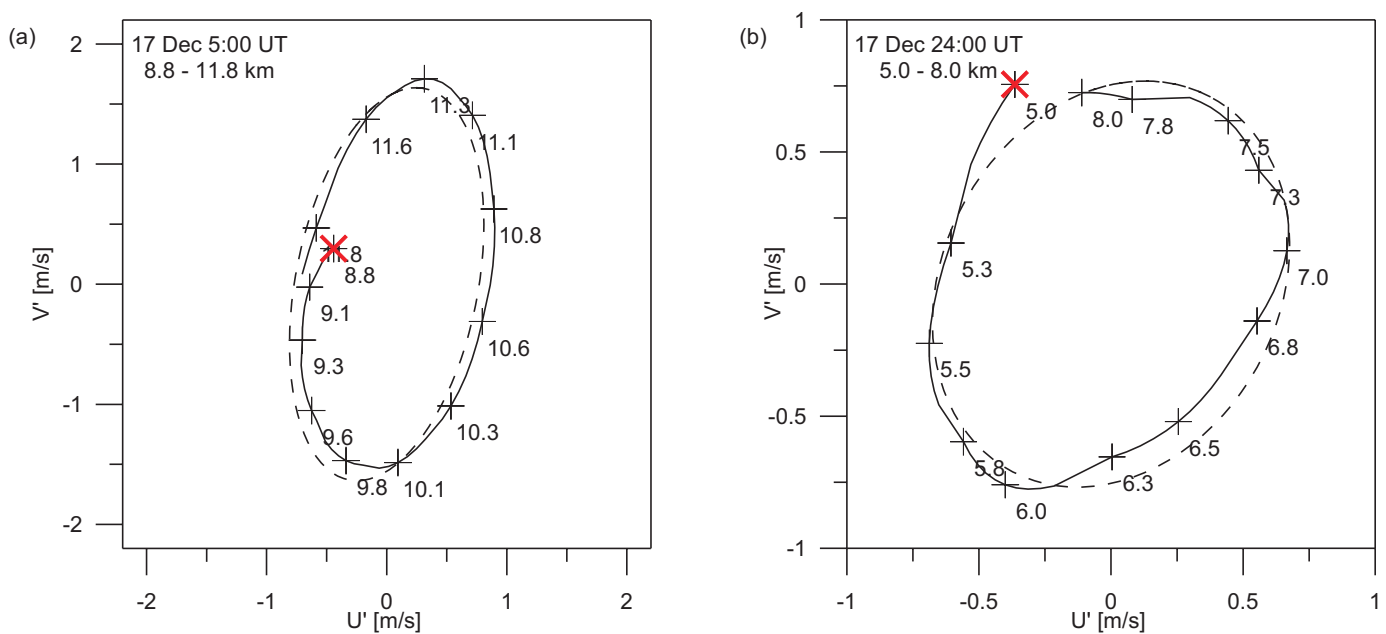

Fig. 8. Results of hodograph analyses for the wind perturbations after band pass filtering with bandwidths of 8-18 h in time and $2-4.5 \mathrm{~km}$ in height (solid line - measured profiles, dashed line - fitted ellipse, $\mathrm{X}$ - starting point of the hodograph), applied to radar measurements at Kühlungsborn (a) and Lindenberg (b).
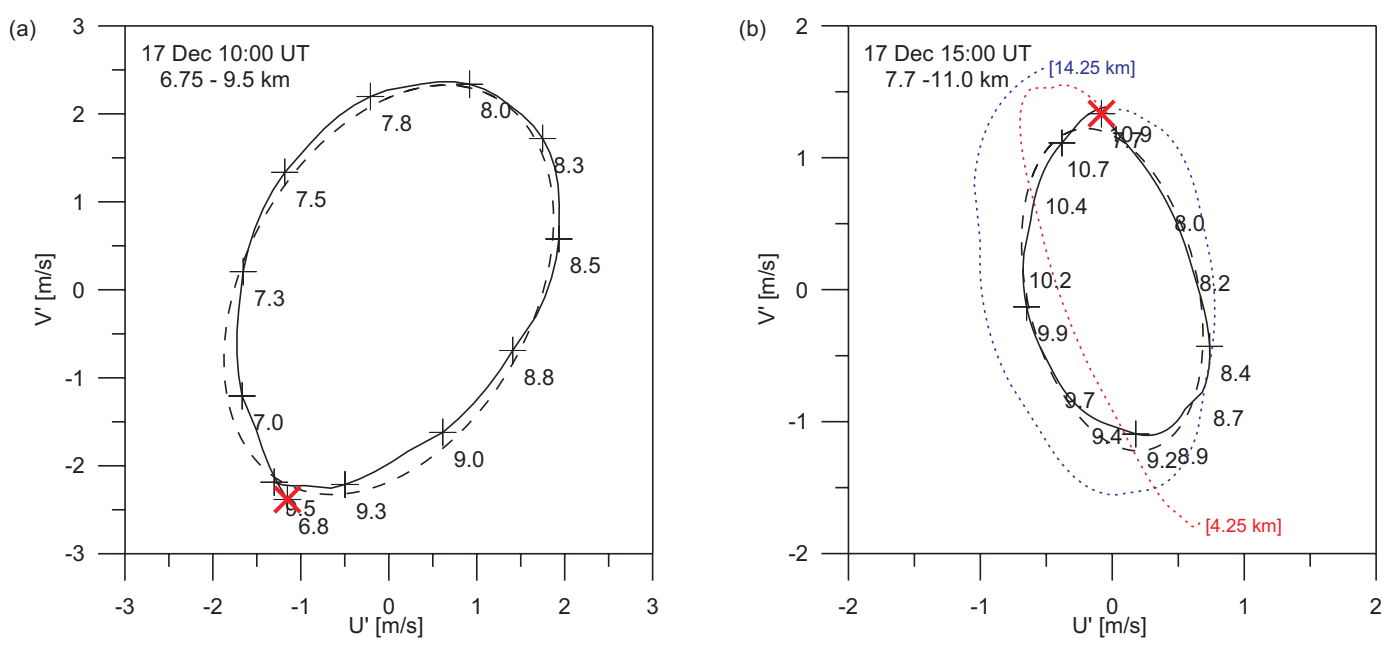

Fig. 9. Results of the hodograph analysis applied on the wind perturbations after band pass filtering with bandwidths of $2-8 \mathrm{~h}$ in time and $2-4.5 \mathrm{~km}$ in height (solid line - measured profiles, dashed line - fitted ellipse, $\mathrm{X}$ - starting point of the hodograph), applied to radar measurements at Kühlungsborn (a) and Lindenberg (b). In (b), the hodograph has been extended from 4.25-7.7 km (red dashed line) and from 11.0-14.25 km (blue dashed line).

wave propagation over a larger height range we have added in the right part (b) of the hodograph in Fig. 9 the wind perturbations from $4.25-7.7 \mathrm{~km}$ and from $11.0-14.25 \mathrm{~km}$, showing the same vertical sense corresponding to upward directed energy propagation with increasing amplitudes at larger heights.

However, the hodograph method represents an instantaneous status and the estimation of gravity wave parameter is only valid for monochromatic waves. Usually a hodograph gives variable results due to the superposition of different waves in the wind profiles. One possibility to determine parameters of IGWs for a given wave number band averaged in time and height will be shown in the next section.

\subsubsection{Stokes-parameter spectra}

The hodograph method is an accurate technique when a large-amplitude monochromatic wave is present in a region of minimal background wind shear. However, hodographs are usually irregular and variable requiring some sorting and classification of large number of profiles to yield a statistical picture of the wave field (Hall et al., 1995). To receive a more statistical description of the gravity wave field the Stokesparameter spectra (Eckermann and Vincent, 1989) can be applied, which is in principle a spectral analogue of the Stokesparameter analysis (Vincent and Fritts, 1987). This method arises from the analogy between partially polarized gravity 
waves and partially polarized electromagnetic waves (Kraus, 1966). To decompose the generally polychromatic wave field, the Stokes parameters are calculated in the Fourier domain (Eckermann and Vincent, 1989). A Fourier transform $U(m)$ and $V(m)$ of the given vertical profiles $u^{\prime}(z)$ and $v^{\prime}(z)$ over their full height ranges yields the following Fourier representations of the profiles:

$U(m)=U_{R}(m)+i U_{I}(m)$

$V(m)=V_{R}(m)+i V_{I}(m)$,

where $m$ is the vertical wave number, $U_{R}, V_{R}$ are real parts of the spectra and $U_{I}, V_{I}$ are imaginary parts of the spectra. From here, Eckermann and Vincent (1989) derived the following power spectral densities for the four Stokes parameters, based on the definitions:

$$
\begin{aligned}
& I=A\left[\overline{U_{R}^{2}(m)}+\overline{U_{I}^{2}(m)}+\overline{V_{R}^{2}(m)}+\overline{V_{I}^{2}(m)}\right] \\
& D=A\left[\overline{U_{R}^{2}(m)}+\overline{U_{I}^{2}(m)}-\overline{V_{R}^{2}(m)}-\overline{V_{I}^{2}(m)}\right] \\
& P=2 A\left[\overline{U_{R}(m) V_{R}(m)}+\overline{U_{I}(m) V_{I}(m)}\right] \\
& Q=2 A\left[\overline{U_{R}(m) V_{I}(m)}-\overline{U_{I}(m) V_{R}(m)}\right] .
\end{aligned}
$$

Overbars denote time averages and $A$ is a constant. The parameter $P$ is the "in-phase" covariance associated with linear polarization, and $Q$ is the "in quadrature" covariance associated with circular wave polarization, while $I$ clearly quantifies the total variance and $D$ defines its axial anisotropy. Consequently, any Stokes parameter $X=\{I, D, P, Q\}$ can now be evaluated over the full range of heights within any wave number band.

$X_{m_{1}, m_{2}}=\int_{m_{1}}^{m_{2}} X(m) d m$.

Then the phase difference $\delta$ between zonal and meridional wind perturbations, the major axis orientation $\Theta$, the averaged ellipse axial ratio $R$ and the degree $d$ of the wave polarization are given by

$$
\begin{aligned}
\delta_{m_{1}, m_{2}} & =\arctan \left(\frac{Q_{m_{1}, m_{2}}}{P_{m_{1}, m_{2}}}\right) \\
\Theta_{m_{1}, m_{2}} & =\frac{1}{2} \arctan \left(\frac{P_{m_{1}, m_{2}}}{D_{m_{1}, m_{2}}}\right) \\
d_{m_{1}, m_{2}} & =\frac{\sqrt{D_{m_{1}, m_{2}}^{2}+P_{m_{1}, m_{2}}^{2}+Q_{m_{1}, m_{2}}^{2}}}{I_{m_{1}, m_{2}}} \\
R_{m_{1}, m_{2}} & =\tan (\xi),
\end{aligned}
$$

where

$\xi=\frac{1}{2} \arcsin \left(\frac{Q_{m_{1}, m_{2}}}{d_{m_{1}, m_{2}} \cdot I_{m_{1}, m_{2}}}\right)$

The phase difference $\delta$ describes the elipticity of the wave: $\delta=0^{\circ}$ or $\delta=180^{\circ}$ indicates linear polarization $(Q=0)$, $\delta=90^{\circ}$ or $\delta=270^{\circ}$ indicates circular polarization $(P=0)$, and anything in between indicates elliptical polarization. These parameters correspond to the hodographs in form of a line, circle or ellipse, respectively. The degree of polarization $d$ quantifies the contribution of the coherent wave motion to the total velocity variance and varies from 0 to 1. The most attractive feature of these parameters is that any partially polarized wave motion can be described completely and uniquely in terms of its Stokes parameters due to the averaging in time and wavenumber bands.

The Stokes parameters calculated for the data from 17 December 1999 are presented in Table 2 for both filtered datasets to investigate the gravity waves with periods at about $12 \mathrm{~h}$ and $6 \mathrm{~h}$. As already mentioned in Sect. 3.2.2, the horizontal wave propagation determined by the major axis orientation $\Theta$ is uncertain by $180^{\circ}$ without additional temperature information or vertical wind from radars. Comparing the mean results derived for intervals of $5 \mathrm{~h}$, we obtained at both locations similar parameters as e.g. the wave propagation directions represented by $\Theta_{m_{1}, m_{2}}$. Note that the averaging times have been selected on the base of the times of maxima of the total variances described by the Stokes parameter $I$, which characterize the mean kinetic energy for the investigated interval and vertical wave number band.

In Sect. 4 the values obtained are used for the final estimation of gravity wave characteristics at each radar location. To identify common wave events over a distance of $\sim 265 \mathrm{~km}$, we will at first apply a simple cross-spectral analysis of the data of both radars.

\subsection{Cross-spectral analysis}

The cross-spectral analysis applied on the measurements of both radars can be used to identify common wave events and to investigate the characteristics of their horizontal propagation (e.g. wavelength or phase velocity) using the phase differences in the wind fluctuations between radars, provided that the wavelength can be resolved by the distance between both stations. After the detection of the appearance of dominating waves in both data sets with wavelet transform as shown in Fig. 3 the cross spectrum (Eq. 22) can be calculated

$S_{U_{1} U_{2}}(\omega)=\frac{<U_{1}(\omega) U_{2}^{*}(\omega)>}{<\left|U_{1}(\omega)\right|^{2}>^{\frac{1}{2}}<\left|U_{2}(\omega)\right|^{2}>^{\frac{1}{2}}}$,

where $U_{1}$ and $U_{2}$ are Fourier transforms of zonal wind time series measured by radar 1 and radar $2, \omega$ is an independent variable in the frequency domain, and brackets denote the averaging in height range defined later. The magnitude of $S_{U_{1} U_{2}}$ is a coherence function, which varies from 0 to 1 . This gives a measure of the correlation between signals from both stations in a given spectral bin. Note that the ensemble averaging in height denoted by the brackets means that the cross spectrum is smoothed, because if no smoothing is carried out, the coherence, regardless of the nature of the processes, is equal to one. The phase value $\Delta \varphi$ of corresponding 
Table 2. Stokes parameters derived from radar measurements at 17 December 1999 for Kühlungsborn (KB1, KB2) and for Lindenberg (LB1, LB2).

\begin{tabular}{lcccc}
\hline & KB1 & LB1 & KB2 & LB2 \\
& Kühlungsborn & Lindenberg & Kühlungsborn & Lindenberg \\
\hline Filter band (time; height) & \multicolumn{2}{c}{$8-18 \mathrm{~h} ; 2-4.5 \mathrm{~km}$} & \multicolumn{2}{c}{ 2-8 h; 2-4.5 km } \\
Averaged time & $00: 00-05: 00 \mathrm{UT}$ & $10: 00-15: 00 \mathrm{UT}$ & $00: 00-05: 00 \mathrm{UT}$ & $07: 00-12: 00 \mathrm{UT}$ \\
\hline \multicolumn{5}{c}{ Stokes parameters } \\
\hline Degree of polarization, $d_{m_{1}, m_{2}}$ & 0.88 & 0.79 & 0.55 & 0.62 \\
Major axis orientation, $\Theta_{m_{1}, m_{2}}$ & $50.5^{\circ}$ & $58.6^{\circ}$ & $77.8^{\circ}$ & $88.1^{\circ}$ \\
Phase difference, $\delta_{m_{1}, m_{2}}$ & $67.5^{\circ}$ & $63.4^{\circ}$ & $79.9^{\circ}$ & $93.9^{\circ}$ \\
Ellipse axial ratio, $R_{m_{1}, m_{2}}$ & 0.66 & 0.58 & 0.66 & 0.40 \\
\hline
\end{tabular}

cross-spectrum maximum gives the time delay $\tau$ between the appearance of the wave maxima at both locations

$\begin{aligned} \Delta \varphi & \sim 360^{\circ} \\ \tau & \sim T_{o b}\end{aligned} \Longrightarrow \tau=T_{o b} \frac{\Delta \varphi}{360^{\circ}}$

where $T_{o b}$ is the observed wave period. Here particular attention must be directed to avoid changes of the phases due to the application of any filtering procedures.

Usually to investigate the spatial characteristics of a wave one need at least three points forming a triangle. Such a method to analyse gravity waves moving across an array of surface-based meteorological atmospheric pressure sensors has been described by Nappo (2002). We applied here the cross-spectral analysis only for a pair of the radars, however using additional information for the wave propagation direction $\alpha$ in relation to the connecting line between radar 1 and radar 2 (Fig. 10). Following the ideas of Nappo (2002), we consider a wave perturbation of some variable, $\Psi$, observed at each station. If we imagine a wave with constant amplitude and horizontal wave vector $\boldsymbol{k}_{\boldsymbol{h}}$ observed at both stations (solid and dashed blue lines on the block-scheme), then the crests or any other phase point of the wave observed at radar $1\left(x_{1}, y_{1}, z_{1}\right)$ at the time $t$ and at radar $2\left(x_{2}, y_{2}, z_{2}\right)$ at the time $t+\tau$ (Fig. 10) correspond to

$$
\begin{aligned}
& \Psi_{1}\left(k x_{1}+l y_{1}+m z_{1}-\omega_{o b} t\right)= \\
& \Psi_{2}\left(k x_{2}+l y_{2}+m z_{2}-\omega_{o b}(t+\tau)\right),
\end{aligned}
$$

where $k, l$, and $m$ are the wave numbers in the $x$-, $y$-, and $z$-directions, respectively. It is assumed that the wave does not change its main characteristics propagating from radar to radar, therefore we can write

$$
\begin{aligned}
& k x_{1}+l y_{1}+m z_{1}-\omega_{o b} t= \\
& k x_{2}+l y_{2}+m z_{2}-\omega_{o b}(t+\tau),
\end{aligned}
$$

which reduces to

$k\left(x_{2}-x_{1}\right)+l\left(y_{2}-y_{1}\right)=\omega_{o b} \tau-m\left(z_{2}-z_{1}\right)$.

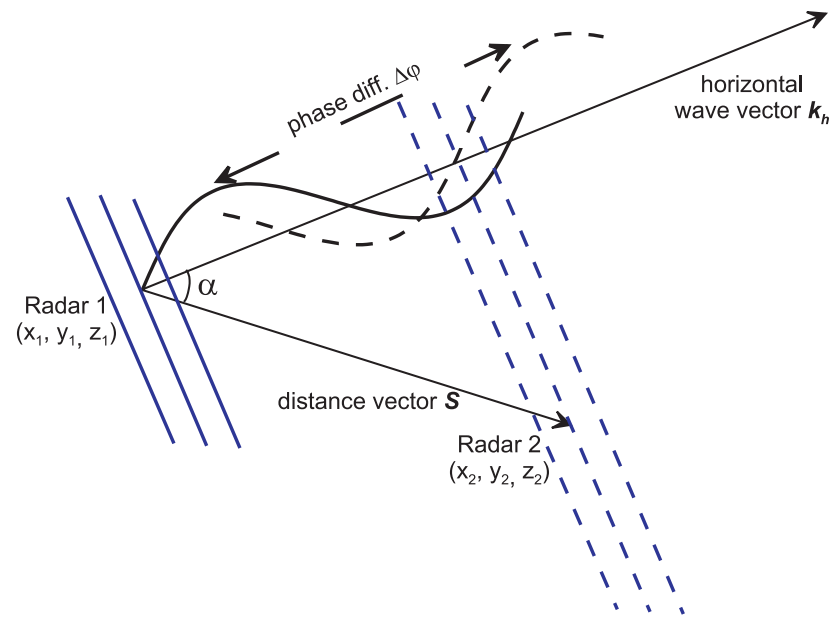

Fig. 10. Block-scheme of IGW propagation.

The left-hand side of the Eq. (26) can be written in vector form as a scalar multiplication of the vectors $\boldsymbol{k}_{\boldsymbol{h}} \cdot \boldsymbol{S}$ or as a multiplication of the vector absolute values with $\cos \alpha$

$\left|\boldsymbol{k}_{\boldsymbol{h}}\right||\boldsymbol{S}| \cos \alpha=\omega_{o b} \tau-m\left(z_{2}-z_{1}\right)$,

where $S$ is the distance vector between both radars and $\alpha$ is the angle between $S$ and the horizontal wave propagation vector $\boldsymbol{k}_{\boldsymbol{h}}$ determined by the propagation direction $\Theta$. Substituting $\omega_{\mathrm{ob}}=2 \pi / T_{\mathrm{ob}}$, the horizontal and vertical wave numbers $k_{h}$ and $m$ by their wavelengths $L_{h}=2 \pi / k_{h}$ and $L_{z}=2 \pi / m$ in Eq. (26) we can write

$L_{h}=\frac{|S| \cos \alpha}{\tau / T_{\mathrm{ob}}-\left(z_{2}-z_{1}\right) / L_{z}}$.

Finally, using the distance between both radars $|\boldsymbol{S}|$ and the time delay $\tau$ between gravity wave events, the ground-based horizontal phase velocity $v_{\mathrm{ph}}^{\mathrm{ob}}$ of the wave propagation can be estimated by

$v_{\mathrm{ph}}^{\mathrm{ob}}=\frac{|\boldsymbol{S}| \cos \alpha}{\tau-\left(z_{2}-z_{1}\right) T_{\mathrm{ob}} / L_{z}}=\frac{\omega_{\mathrm{ob}}}{k_{h}}$. 

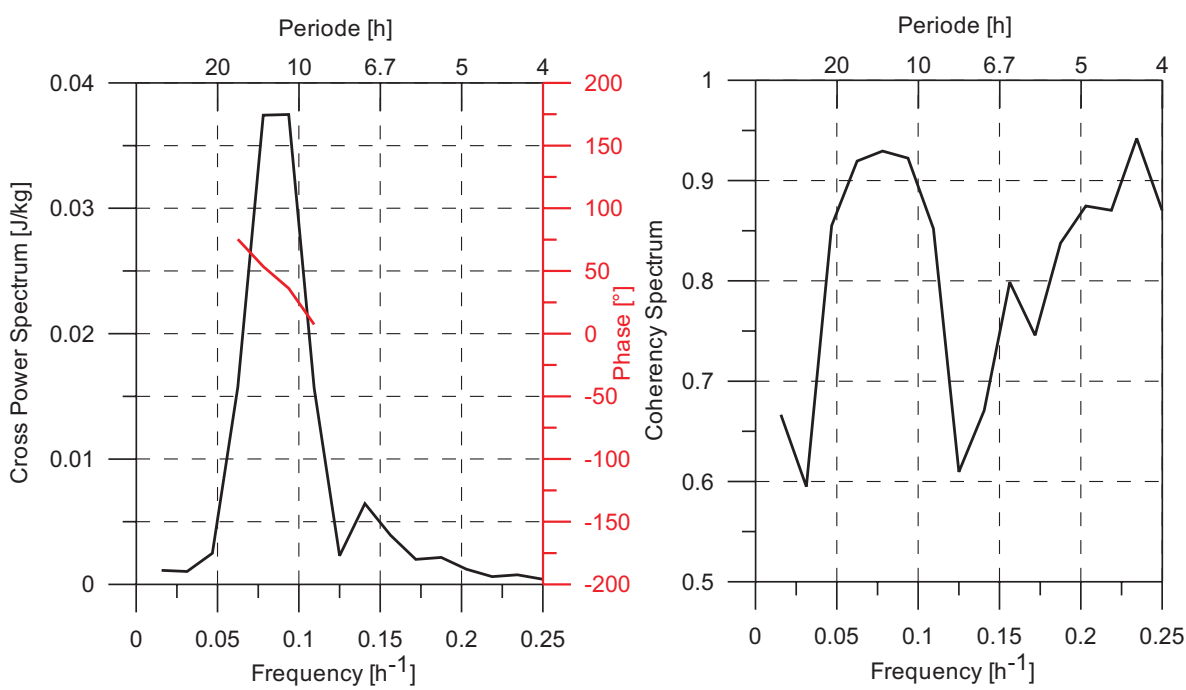

Fig. 11. Cross-power spectrum between radar measurements at Kühlungsborn and Lindenberg for the time from 17 December 1999 , 00:00 UT to 18 December 1999, 00:00 UT, averaged over the height range from $5.25 \mathrm{~km}$ to $7.75 \mathrm{~km}$. Left part: Amplitude (black) and phase difference (red). Right part: Coherency spectra.

The cross-correlation spectrum of the zonal winds measured at Kühlungsborn and Lindenberg, presented in the left part of Fig. 11, has been averaged over the altitude range between 5.25 and $7.75 \mathrm{~km}$. The amplitude of the cross spectrum shows a dominating common wave with an observed period of about $11.4 \mathrm{~h}$ which is in good agreement with the dominating period estimated by the wavelet transforms of the time series at both locations as shown in Fig. 3a, c. The significance of this wave is proved by the coherency spectrum shown in the right part of Fig. 11. Due to the slopes of the phase lines in Fig. 4 and the downward energy propagation with a vertical wavelength of about $3.3 \mathrm{~km}$ shown by the rotary spectra (Fig. 6) and hodograph analyses (Fig. 8), the observed period of $11.4 \mathrm{~h}$ is negative (Eq. 8). The phase difference (red line in Fig. 11) of about $\pm 40^{\circ}$ or $\mp 320^{\circ}$ between the maxima of this wave at both locations corresponds to an amount of a time delay $\tau$ of about $1.3 \mathrm{~h}$ or $10.1 \mathrm{~h}$, respectively, where the sign depends on the sign of the observed frequency itself.

To check the reliability of this method, we have applied Eqs. (28) and (29) using the radar coordinates and the observed period $2 \pi / \omega_{\mathrm{ob}}$ of $-11.4 \mathrm{~h}$. With the detected time delay of $-1.3 \mathrm{~h}$ and $+10.1 \mathrm{~h}$, we found consistent values for the horizontal wave numbers $k_{h}$ and ground based horizontal phase velocities $v_{\mathrm{ph}}^{\mathrm{ob}}$ directly estimated from the crossspectral analysis. In Table 3 the results are shown derived with different assumed wave directions $\Theta$ or the corresponding angle $\alpha$. Based on mean vertical phase velocities with an amount of about $0.06-0.10 \mathrm{~ms}^{-1}$ we have added different height shifts $z_{2}-z_{1}$ in order to study the variability of the derived wave parameter. We define here and in the following that a wavelength will be negative if the corresponding wave number $k$ or $m$ are negative.
We started at first with a time delay of $10.1 \mathrm{~h}$ (case A) with the assumption that the wave is moving in the same direction as the jet-maximum at about $9 \mathrm{~km}$, which differs from the zonal direction (case B) by only $6^{\circ}$. In both examples, the estimated horizontal wavelengths of about $-634 \mathrm{~km}$ (case A) or $-557 \mathrm{~km}$ (case B) for a height shift of about $2 \mathrm{~km}$ are in same order with the horizontal wavelength in the zonal direction estimated in P2003.

Further a time delay of $-1.3 \mathrm{~h}$ was used. In case (C), we have used the major axis orientation of the wave direction $\Theta \approx 54^{\circ}$ estimated by the Stokes-parameter analysis applied for the dominating waves with periods of about $12 \mathrm{~h}$ and filtered with bandwidths between 8 and $18 \mathrm{~h}$ (see Table 2). Note that in this case the directions of the wave propagation at both locations differ by only $8^{\circ}$ so that there are no ambiguities to estimate $\alpha$ and to apply the cross-spectral analysis. This time delay with a mean vertical phase velocity of about $0.10 \mathrm{~ms}^{-1}$ leads to a realistic height shift in the order of about $-500 \mathrm{~m}$. Using these values we obtained a horizontal wavelength of about $-300 \mathrm{~km}$ and an observed horizontal phase speed of $7.3 \mathrm{~ms}^{-1}$ (case C). We will discuss these results in the next Sect. 4 together with the results separately estimated at each radar location. To check the sensibility on the final results, we have added in case (C) a 10\% change to the realistic height shift, leading to variations of about $10 \%$ in the horizontal wavelength, and of about $5 \%$ in the observed horizontal phase speed, respectively.

\section{Gravity wave characteristics and discussion}

To estimate the gravity waves characteristics such as intrinsic frequency $\omega_{\text {in }}$ and horizontal wavenumber $k_{h}$, the phase and group velocities for each radar location separately, the 
Table 3. Horizontal wavelengths and ground-based phase speeds as derived from the cross-spectral analysis in dependence on the wave direction and the vertical height shift for an observed period $2 \pi / \omega_{\mathrm{ob}}$ of $-11.4 \mathrm{~h}$ and a distance $|\boldsymbol{S}|$ between both radars of $265 \mathrm{~km}$.

\begin{tabular}{|c|c|c|c|c|c|c|}
\hline Case & $\begin{array}{c}\text { Time delay } \\
\tau, \mathrm{h}\end{array}$ & $\begin{array}{c}\text { Major axis orientation } \\
\Theta,^{\circ}\end{array}$ & $\begin{array}{c}\text { Angle between } \boldsymbol{k}_{\boldsymbol{h}} \text { and } \boldsymbol{S} \\
\alpha,{ }^{\circ}(\text { Fig. } 10)\end{array}$ & $\begin{array}{l}\text { Vertical shift } \\
\qquad \Delta z, \mathrm{~km}\end{array}$ & $\begin{array}{l}\text { Horizontal wavelength } \\
2 \pi / k, \mathrm{~km}\end{array}$ & $\begin{array}{l}\text { Observed horizontal phase speed } \\
\qquad v_{\mathrm{ph}}^{\mathrm{ob}}, \mathrm{ms}^{-1}\end{array}$ \\
\hline (A) & 10.1 & -6 & 48 & $\begin{array}{c}0 \\
-1.0 \\
-2.0\end{array}$ & $\begin{array}{l}-200 \\
-304 \\
-634\end{array}$ & $\begin{array}{c}4.9 \\
7.4 \\
15.4\end{array}$ \\
\hline (B) & 10.1 & 0 & 54 & $\begin{array}{c}0 \\
-1.0 \\
-2.0\end{array}$ & $\begin{array}{l}-176 \\
-267 \\
-557\end{array}$ & $\begin{array}{c}4.3 \\
6.5 \\
13.6\end{array}$ \\
\hline (C) & -1.3 & 54 & 108 & $\begin{array}{c}0 \\
-0.5(-0.45 ;-0.55) \\
-1.0\end{array}$ & $\begin{array}{c}-714 \\
-307(-325 ;-290) \\
-195\end{array}$ & $\begin{array}{c}17.4 \\
7.3(7.8 ; 6.9) \\
4.8\end{array}$ \\
\hline
\end{tabular}

following three relations will be used. The polarization relation is given by

$R=\left|\frac{f}{\omega_{\text {in }}}-\frac{k_{h}}{m \omega_{\text {in }}} \frac{\partial \bar{V}}{\partial z}\right|$,

where $R$ is the averaged axial ellipse ratio, and $z$ is the altitude. In contrast to Eq. (9) here the vertical wind shear effect in the background wind, as introduced by Hines (1989), is included by the term $\frac{\partial \bar{V}}{\partial z}$, where $\bar{V}$ denotes the mean horizontal wind component perpendicular to the wave propagation. This is important if the wave vector is nearly perpendicular to the up-stream direction. The dispersion relationship is given by

$\omega_{\text {in }}^{2}=f^{2}+\frac{N^{2} k_{h}^{2}}{m^{2}}-\frac{2 f k_{h}}{m} \frac{\partial \bar{V}}{\partial z}$,

where $N$ is the angular Brunt-Väisälä frequency. Finally, the Doppler relation is given by Eq. (2).

For a given location, the Coriolis frequency has been calculated by

$f=2 \cdot 7.292 \cdot 10^{-5} \mathrm{~s}^{-1} \cdot \sin \phi$,

where $\phi$ is geographical latitude. The Brunt-Väisälä frequency $N(z)$ can be estimated from radiosonde temperature soundings, but here we are using mean values of $0.013 \mathrm{~s}^{-1}$ for the troposphere and of $0.021 \mathrm{~s}^{-1}$ for the stratosphere, respectively.

The mean background horizontal wind component $\bar{U}$ in the direction of the wave propagation and the horizontal wind component $\bar{V}$ perpendicular to the wave propagation are estimated by

$$
\begin{aligned}
& \bar{U}=U_{x} \cos \Theta+V_{y} \sin \Theta \\
& \bar{V}=-U_{x} \sin \Theta+V_{y} \cos \Theta,
\end{aligned}
$$

where $U_{x}$ and $V_{y}$ are the observed zonal and meridional winds, and $\Theta$ is the direction of the wave propagation calculated with Stokes-parameter analysis. Finally the vertical wind shear term $\partial \bar{V} / \partial z$ has been estimated.
The intrinsic horizontal and vertical phase velocities are

$$
\left(v_{\mathrm{ph}}, v_{\mathrm{pz}}\right)=\left(\frac{\omega_{\text {in }}}{k_{h}}, \frac{\omega_{\text {in }}}{m}\right) .
$$

The intrinsic horizontal and vertical components of the group velocity are given by

$c_{\text {gh }}=\frac{\partial \omega_{\text {in }}}{\partial k_{h}}=\frac{N^{2} k_{h}}{\omega_{\text {in }} m^{2}}-\frac{f}{\omega_{\text {in }} m} \frac{\partial \bar{V}}{\partial z}$

$c_{\mathrm{gz}}=\frac{\partial \omega_{\mathrm{in}}}{\partial m}=-\frac{N^{2} k_{h}^{2}}{\omega_{\mathrm{in}} m^{3}}+\frac{f k_{h}}{\omega_{\mathrm{in}} m^{2}} \frac{\partial \bar{V}}{\partial z}$.

The ground-based horizontal group velocity relative to observer is then given by

$c_{\mathrm{gh}}^{\mathrm{ob}}=\frac{\partial \omega_{\mathrm{ob}}}{\partial k_{h}}=c_{\mathrm{gh}}+\bar{U}$.

The observed frequency $\omega_{\mathrm{ob}}$ and the vertical wave number $m$ can be derived e.g. by wavelet transforms or spectral analyses of the wind measurements.

We have used two ways to solve Eqs. (30), (31) and (2). If the ellipse ratio $R$ and $\omega_{\mathrm{ob}}$ are given then the intrinsic frequency $\omega_{\text {in }}$, the horizontal wavenumber $k_{h}$ and the vertical wavenumber $m$ can be estimated by solving the polarization relation Eq. (30), the dispersion relation Eq. (31) and the Doppler relation Eq. (2). In the second way, the ellipse ratio $R$ and the vertical wavenumber $m$ are given by the evaluation of the spectra with respect to height. Then the Eqs. (30) and (31) have to be solved to estimate the intrinsic frequency $\omega_{\text {in }}$ and the horizontal wavenumber $k_{h}$.

To investigate the gravity waves with observed periods of about $12 \mathrm{~h}$, we follow the first way to solve the Eqs. ( 30 ), (31) and (2) using the Stokes parameter shown in the left part of Table 2 and the mean winds $\bar{U}, \bar{V}$ estimated with Eq. (33) from the dominating jet stream at the height of about $9 \mathrm{~km}$ (see e.g. Fig. 2). To resolve the ambiguities in the polarization relation Eq. (30) and in the quadratic dispersion relation Eq. (31) and to determine the signs of the wave numbers 
Table 4. Gravity waves parameters at about $9 \mathrm{~km}(\mathbf{K B 1}, \mathbf{L B 1})$ and $6 \mathrm{~km}(\mathbf{K B 2}, \mathbf{L B 2})$ derived from the results of the Stokes-parameter analysis as shown in Table 2 for the radar measurements at Kühlungsbon (KB1, KB2) and Lindenberg (LB1, LB2).

\begin{tabular}{|c|c|c|c|c|}
\hline & $\begin{array}{l}\text { KB1 } \\
\text { Kühlungsborn }\end{array}$ & $\begin{array}{c}\text { LB1 } \\
\text { Lindenberg }\end{array}$ & $\begin{array}{c}\text { KB2 } \\
\text { Kühlungsborn }\end{array}$ & $\begin{array}{c}\text { LB2 } \\
\text { Lindenberg }\end{array}$ \\
\hline \multirow[t]{2}{*}{ Filter band (time; height) } & \multicolumn{2}{|c|}{$8-18 \mathrm{~h} ; 2-4.5 \mathrm{~km}$} & \multicolumn{2}{|c|}{$2-8 \mathrm{~h} ; 2-4.5 \mathrm{~km}$} \\
\hline & \multicolumn{4}{|c|}{ IGW parameters } \\
\hline $\begin{array}{l}\text { Mean horizontal wind, } \bar{U}, \mathrm{~ms}^{-1} \\
\text { (in the wave propagation direction) }\end{array}$ & 17 & 18 & 2.9 & -1.3 \\
\hline Wind shear component, $\partial \bar{V} / \partial z, \mathrm{~s}^{-1}$ & $2.8 \times 10^{-3}$ & $-0.5 \times 10^{-3}$ & $-1.7 \times 10^{-3}$ & $1.4 \times 10^{-3}$ \\
\hline Observed period, $2 \pi / \omega_{o b}, \mathrm{~h}$ & -11.4 & -11.4 & 6.4 & 6.4 \\
\hline Intrinsic period, $2 \pi / \omega_{i n}, \mathrm{~h}$ & 7.7 & 8.3 & 8.3 & 6.0 \\
\hline Horizontal wavelength, $2 \pi / k_{h}, \mathrm{~km}$ & -281 & -313 & 225 & 158 \\
\hline Vertical wavelength, $2 \pi / m, \mathrm{~km}$ & 3.3 & 3.6 & -3.2 & -3.2 \\
\hline Horizontal phase velocity, $v_{\mathrm{ph}}, \mathrm{ms}^{-1}$ & -10.1 & -10.3 & 7.5 & 7.3 \\
\hline Vertical phase velocity, $v_{\mathrm{pz}}, \mathrm{ms}^{-1}$ & 0.11 & 0.12 & -0.1 & -0.15 \\
\hline Horizontal group velocity, $c_{\mathrm{gh}}, \mathrm{ms}^{-1}$ & -6.6 & -7.3 & 5.6 & 6.2 \\
\hline Vertical group velocity, $c_{\mathrm{gz}}, \mathrm{ms}^{-1}$ & -0.08 & -0.08 & 0.08 & 0.12 \\
\hline
\end{tabular}

we used in addition the slopes of the constant phase lines Eq. (8) in the wind perturbations (Fig. 4) in comparison with the downward energy propagation as estimated by the rotary spectra (Fig. 6).

The derived gravity wave characteristics are given in Table 4 , resulting in consistent parameters at both locations like the horizontal wavelengths as well as the group and phase velocities. The dispersion relation leads here to vertical wavelengths between 3.3 and $3.6 \mathrm{~km}$, which are in the order of the results of the wavelet analyses (see Fig. 3) or the rotary spectra (Fig. 6). Note, that the relation

$v_{\mathrm{ph}}=\frac{\omega_{\text {in }}}{k_{h}}=\frac{\omega_{\mathrm{ob}}}{k_{h}}-\bar{U}$

between the intrinsic and the ground-based horizontal phase speed is only fulfilled if the intrinsic phase speed $v_{\mathrm{ph}}$ and hence the horizontal wavenumber $k_{h}$ are negative.

Then the intrinsic phase velocities $v_{\mathrm{ph}_{c}}$ estimated from the cross-spectral analysis, $\left(v_{\mathrm{ph}}^{\mathrm{ob}}=7.3 \mathrm{~ms}^{-1}\right.$, see Table 3 and case $\mathrm{C}$ therein) for the wave direction against the background wind $\bar{U}$ and using the mean winds at both locations (Table 4) parallel to the wave direction

$v_{\mathrm{ph}}=v_{\mathrm{ph}}^{\mathrm{ob}}-\bar{U}$

yields values of $-9.5 \mathrm{~ms}^{-1}$ and $-10.5 \mathrm{~ms}^{-1}$, which agree very well with the results $v_{\mathrm{ph}}$ separately estimated for Kühlungsborn $\left(-10.1 \mathrm{~ms}^{-1}\right)$ and Lindenberg $\left(-10.3 \mathrm{~ms}^{-1}\right.$, see Table 4), respectively.

Thus, the results estimated for each radar location and leading to negative wave numbers $k_{h}$ and horizontal wavelengths of about $300 \mathrm{~km}$ confirm the results derived directly from the cross-spectral analysis, using the mean wave directions estimated from the Stokes-parameter analysis and a re- alistic height shift of $-500 \mathrm{~m}$ corresponding to a mean vertical phase velocity $v_{\mathrm{pz}}$ of about $0.1 \mathrm{~ms}^{-1}$ for the time delay of $-1.3 \mathrm{~h}$.

We have to note for the case investigated here, that the estimations of the horizontal wavelengths depend primarily on changes in the component of the mean background wind parallel to the wave direction as used in the Doppler relation Eq. (2), whereas the influence of the vertical wind shears effects used in Eqs. (30) and (31) leads to changes in the intrinsic period of $1.6 \mathrm{~h}$ and in the horizontal wavelength of about $40 \mathrm{~km}$.

For the waves with observed periods of about $6 \mathrm{~h}$ the sign of $\omega_{\mathrm{ob}}$ must be positive due to the slopes of the phase lines in Fig. 5 and the upward energy propagation (Fig. 7) (see Eq. 8). In this case we found self-contained solutions applying the second way based on a given ellipse ratio $R$ and the vertical wavenumber $m$, estimated by the evaluation of the spectra with respect to height and using the Stokes-parameter shown in the right part of Table 2. The solution of Eqs. (30) and (31) leads to the estimation of the intrinsic frequency $\omega_{\text {in }}$ and the horizontal wavenumber $k_{h}$ for a height of about $6 \mathrm{~km}$ as in Table 4. Note that in this case the sign of the wavenumber $k_{h}$ must be positive to fulfill Eq. (38). Therefore we conclude that these less pronounced waves with horizontal wavelengths in the order of about $200 \mathrm{~km}$ are moving with the wind. Due to their upward directed energy propagation (Fig. 7) we can only speculate that a possible source for these waves could be connected with frontal activity or deep convection in the boundary layer. This also could be the reason why these waves didn't show up in the two stations at the same time, as already shown by the wavelet analyses (Fig 3a, c). 
We can summarize, that we found two wave classes with different energy propagation directions during this case study at both radar sites. Both wave classes show downward phase propagations. Connected with a jet stream in the upper troposphere and due to the shift in the frequency by the Dopplereffect, the dominating wave with an observed period $-11.4 \mathrm{~h}$ shows a downward energy propagation in the troposphere. The analysis also shows that the direction of the wave propagation is upstream, and the intrinsic period is $\sim 8 \mathrm{~h}$. Horizontal wave numbers for this wave are negative and vertical wave numbers are positive at both locations with corresponding wavelengths between -281 and $-313 \mathrm{~km}$ as well as between 3.3 and $3.5 \mathrm{~km}$, respectively, and are in the same order as the results derived directly from the cross-spectral analysis (see Sect. 3.3 and case C in Table 3).

Additionally to this wave class, we detected another one with shorter horizontal wavelengths and a smaller observed period of $6.4 \mathrm{~h}$, which has an upward directed energy propagation. The horizontal and vertical wavelengths of this wave are $\sim 200 \mathrm{~km}$ and $-3.2 \mathrm{~km}$, respectively.

\section{Conclusions}

In the frame of a case study to investigate the properties of inertia-gravity waves over Northern Germany in connection with a jet stream in the upper troposphere during a Rossby wave breaking event (see P2003) we used continuous radar measurements with the OSWIN VHF radar at Kühlungsborn and the UHF Wind Profiler at Lindenberg. Both sites are separated by about $265 \mathrm{~km}$. Wavelet analysis have been described and applied to consider the height and time dependence of the wave packages, to identify comparable inertiagravity wave events at the two locations. Based on the estimated vertical wavelengths of about $2-4 \mathrm{~km}$ near the tropopause region from the wavelet transforms of the vertical wind profiles averaged in time, and the detected dominant observed periods of about 11-12 $\mathrm{h}$ together with a less pronounced period of about $6 \mathrm{~h}$ derived from the wavelet transform of the wind time series, suitable filter parameters have been specified to determine the wind perturbations applying the Fourier technique as filtering routine. We found for both periods dominating downward phase propagating perturbations. The rotary spectra as well as the hodographs indicate a downward directed energy propagation for the dominating period of about $12 \mathrm{~h}$ which is in agreement with the results in P2003, whereas the detected waves with periods of about $6 \mathrm{~h}$ show an upward directed energy propagation.

The Stokes-parameter analysis is the most reliable method to estimate gravity wave parameters. The solution of the equations based on the linear theory led to the identification of dominant gravity waves with characteristic horizontal wavelengths of about $300 \mathrm{~km}$ moving against the background wind. Further, the occurrence of a secondary less pronounced wave with a horizontal wavelength in the order of about $200 \mathrm{~km}$ moving with the wind has been found using the Stokes analysis and solving the dispersion and polarization relation.

The independent analyses of the radar measurements at both locations lead to consistent results. The cross-spectral analysis between the data of both radars have been used to prove the coherence of a common wave event over the distance of about $265 \mathrm{~km}$ taking into account its vertical propagation and to estimate directly the horizontal wavelengths of $-300 \mathrm{~km}$ for wave moving against the jet stream as well as the corresponding phase velocities, which are in a good agreement with the results estimated separately at each location. In contrast to the way to solve the Eqs. (30), (31) and (2) as described in Sect. 4, this very simple method uses only the geometry, the phase differences of coherent waves at both locations and the mean direction of the wave propagation vector which should not differ significantly between the two radar stations. To avoid this latter condition and to get more statistical reliability, data from more radar stations should be used. The DWD-UHF wind profiler at Ziegendorf (Lehmann et al., 2003), in operation since January 2004 and forming a triangle with Lindenberg and Kühlungsborn over Northern Germany, improve investigations of the spatial gravity wave characteristics in future. Further investigations will be directed at comparing the obtained results with the output of the mesoscale MM5 model, applied for the description of the dynamics for the selected events, and organized for neighboring locations with a sufficient resolution in time and height.

Acknowledgements. The authors thank W. Singer, D. Keuer and M. Zecha for the management and the support to operate the VHF radar at Kühlungsborn. Helpful discussions with C. Zülicke and M. Rapp are highly appreciated. The investigations are part of the LEWIZ project, supported by the German Ministry of Education and Research (BMBF) under the framework program AFO 2000.

Edited by: G. Vaughn

\section{References}

Buss, S., Hertzog, A., Hostetter, C., Bui, T. P., Lüthi, D., and Wernli, H.: Analysis of a jet stream induced gravity wave associated with an observed ice cloud over Greenland, Atmos. Chem. Phys., 4, 1183-1200, 2004,

SRef-ID: 1680-7324/acp/2004-4-1183.

Cot, C. and Barat, J.: Wave-turbulence interaction in the stratosphere: A case study, J. Geophys. Res., 91, 2749-2756, 1986.

Dörnbrack, A., Birner, T., Fix, A., Flentje, H., Meister, A., Schmid, H., Browell, E., and Mahoney, M.: Evidence for inertia gravity waves forming polar stratospheric clouds over Scandinavia, J. Geophys. Res., 107, D20, 8287, doi:10.1029/2001JD000452, 2002.

Eckermann, S.: Hodographic analysis of gravity waves: Relationships among Stokes parameters, rotary spectra and cross-spectral methods, J. Geophys. Res., 101, 19 169-19 174, 1996. 
Eckermann, S. and Vincent, R.: Falling sphere observations gravity waves motions in the upper stratosphere over Australia, Pure Appl. Geophys., 130, 509-532, 1989.

Farge, M.: Wavelet transforms and their applications to turbulence, Annu. Rev. Fluid Mech., 24, 395-457, 1992.

Fritts, D. C. and Alexander, M. J.: Gravity wave dynamics and effects in the middle atmosphere, Rev. Geophys., 41, 1, 1003, doi:10.1029/2001RG000106, 2003.

Gill, A. E.: Atmosphere-Ocean Dynamics, Academic Press, 1982.

Guest, F. M., Reeder, M. J., Marks, C. J., and Karoly, D. J.: Inertiagravity waves observed in the lower stratosphere over Macquarie Island, J. Atmos. Sci., 57, 737-752, 2000.

Gurvich, A., Kon, A., and Tatarskii, V.: Scattering of elecromagnetic waves on sound in connection with problems of atmospheric sounding (review), Radiophys. Quant. Electron., 30, 347-366, 1987.

Hall, G. E., Meek, C. E., and Manson, A. H.: Hodograph analysis of mesopause region winds observed by three MF radars in the Canadian prairies, J. Geophys. Res., 100, 7411-7421, 1995.

Hines, C. O.: Tropopausal mountain waves over Arecibo: A case study, J. Atmos. Sci., 46, 476-488, 1989.

Hogg, D., Decker, M., Guiraud, F., Earnshaw, K., Merritt, D., Moran, K., Sweezy, W., Strauch, R., Westwater, E., and Little, C.: An automatic profiler of the temperature, wind and humidity in the troposphere, J. Clim. Appl. Meteorol., 22, 807-831, 1983.

Kraus, J.: Radioastronomy, McGraw-Hill, New York, 1966.

Lehmann, V., Dibbern, J., Görsdorf, U., Neuschaefer, J., and Steinhagen, H.: The new operational UHF Wind Profiler Radars of the Deutscher Wetterdienst, in Proceedings of the Sixth International Symposium on Tropospheric Profiling: Needs and Technologies, Leipzig, Germany, edited by U. Wandinger, R. Engelmann, and K. Schmieder, pp. 489-491, Institute for Tropospheric Research, 2003.

Merritt, D. A.: A statistical averaging method for wind profiler doppler spectra, J. Atmos. Ocean. Techn., 12, 985-995, 1995.

Nappo, C. J.: An introduction to atmospheric gravity waves, Academic Press, 2002.
Pavelin, E. and Whiteway, J.: Gravity wave interactions around the jet stream, Geophys. Res. Lett., 29, 21, 2024, doi:10.1029/2002GL015783, 2002.

Peters, D. and Waugh, D.: Influence of barotropic shear on the poleward advection of upper tropospheric air, J. Atmos. Sci., 53, 3013-3031, 1996.

Peters, D., Hoffmann, P., and Alpers, M.: On the appearance of inertia gravity waves on the north-easterly side of an anticyclone, Meteor. Z., 12, 25-35, 2003.

Plougonven, R., Teitelbaum, H., and Zeitlin, V.: Inertia gravity wave generation by the tropospheric midlatitude jet as given by the Fronts and Atlantic Storm-Track Experiment, J. Geophys. Res., 108, D21, 4686, doi:10.1029/2003JD003535, 2003.

Röttger, J.: ST radar observations of atmospheric waves over mountainous areas: a review, Ann. Geophys., 18, 750-765, 2000, SRef-ID: 1432-0576/ag/2000-18-750.

Sato, K., O'Sullivan, D. J., and Dunkerton, T. J.: Low-frequency inertia-gravity waves in the stratosphere revealed by three week continuous observation with the MU radar, Geophys. Res. Lett., 24, 1739-1742, 1997.

Thomas, L., Worthington, R., and McDonald, A. J.: Inertia-gravity waves in the troposphere and lower stratosphere, Ann. Geophys. 17, 115-121, 1999,

SRef-ID: 1432-0576/ag/1999-17-115.

Thompson, R. O. R. Y.: Observation of inertial waves in the stratosphere, Quart. J. R. Met. Soc., 104, 691-698, 1978.

Torrence, C. and Compo, G. P.: A practical guide to wavelet analysis, Bull. Amer. Meteor. Soc., 79, 61-78, 1998.

Vincent, R. and Fritts, D.: A climatology of gravity wave motions in the mesopause region at Adelaide, Australia, J. Atmos. Sci., 44, 748-760, 1987.

Zink, F. and Vincent, R.: Wavelet analysis of stratospheric gravity wave packets over Macquarie Island, J. Geophys. Res., 106, 10 275-10 288, 2001. 